\title{
NT-proBNP and exercise capacity in adult patients with congenital heart disease and a prosthetic valve: a multicentre PROSTAVA study
}

\author{
R. C. Schoonbeek ${ }^{1,2} \cdot$ P. G. Pieper ${ }^{1}$ Y. J. van Slooten ${ }^{1,2,4}$ • H. G. Freling ${ }^{1,3,4} \cdot$ G. T. Sieswerda ${ }^{5}$ A. P. J. van \\ Dijk $^{6}$ - M. R. M. Jongbloed ${ }^{7}$ M. C. Post ${ }^{8} \cdot$ B. J. Bouma9 $\cdot$ R. M. F. Berger ${ }^{1} \cdot$ T. Ebels ${ }^{2}$ J. P. van Melle ${ }^{1}$
}

Published online: 12 September 2016

(C) The Author(s) 2016. This article is available at SpringerLink with Open Access.

\begin{abstract}
Objectives N-terminal B-type natriuretic peptide (NTproBNP) is an important biomarker for the detection of heart failure. Adults with congenital heart disease (ACHD) and a prosthetic heart valve are at risk for heart failure. This study aimed to determine the value of NT-proBNP in ACHD patients with a prosthetic valve and investigate its relationship with cardiac function and exercise capacity.

Methods In this multi-centre cross-sectional observational study, data regarding medical history, echocardiography, exercise testing $\left(\mathrm{VO}_{2}\right.$ peak) and laboratory blood evaluation (including NT-proBNP) were collected in ACHD patients with a single prosthetic valve (either homografts, heterografts or mechanical valves).

J. P. van Melle

j.p.van.melle@umcg.nl

1 Department of Cardiology, University Medical Center Groningen, University of Groningen, Groningen, The Netherlands

2 Department of Thoracic Surgery, University Medical Center Groningen, University of Groningen, Groningen, The Netherlands

3 Department of Radiology, University Medical Center Groningen, University of Groningen, Groningen, The Netherlands

4 Interuniversity Cardiology Institute of the Netherlands, Utrecht, The Netherlands

5 University Medical Center Utrecht, Utrecht, The Netherlands

6 Radboud University Medical Center, Nijmegen, The Netherlands

7 Leiden University Medical Center, Leiden, The Netherlands

8 St. Antonius Hospital, Nieuwegein, The Netherlands

9 Academic Medical Center, Amsterdam, The Netherlands
\end{abstract}

Results A total of 306 ACHD patients with pulmonary valve replacement (PVR, $n=139$ ), aortic valve replacement $(n=141)$, mitral valve replacement $(n=21)$ or tricuspid valve replacement $(n=5)$ were investigated. The majority of patients $(77 \%)$ were in NYHA class I or II. Elevated NTproBNP levels (cut-off $\geq 125 \mathrm{pg} / \mathrm{ml}$ ) were found in $50 \%$ of the patients, with the highest levels in patients with mitral valve replacements. In this study population, NT-proBNP levels were associated with gender $(p=0.029)$ and $\mathrm{VO}_{2} \max$ $(p<0.001)$. In PVR patients, NT-proBNP levels were associated with lower $\mathrm{VO}_{2}$ peak, also after adjustment for age, gender and age at valve replacement in a multivariate model $(p=0.015)$.

Conclusions In patients with ACHD and a prosthetic valve, elevated NT-proBNP levels are frequently observed despite preserved NYHA class. In PVR patients, a higher NTproBNP level was associated with a lower $\mathrm{VO}_{2}$ peak. These results may be of importance in the ongoing discussion about the timing of valve replacement in patients with CHD.

Keywords Congenital heart disease $\cdot$ Pulmonary valve replacement $\cdot$ NT-proBNP

\section{Introduction}

$\mathrm{N}$-terminal B-type natriuretic peptide (NT-proBNP) is a well-established marker of heart failure (HF) and a predictor of impaired cardiovascular prognosis [1]. The value of NT-proBNP has been investigated in many patient populations, including patients with acute and chronic $\operatorname{HF}[2,3]$ and patients with valvular heart disease [4]. Remarkably, data on NT-proBNP in adult patients with congenital heart disease (ACHD) are scarce. A cross-sectional study among patients with all types of ACHD showed that NT-proBNP 


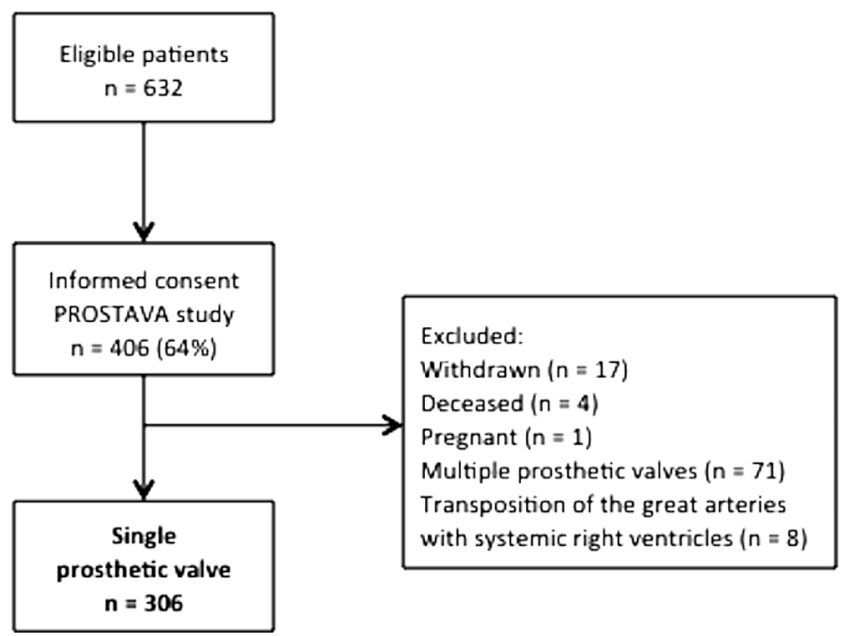

Fig. 1 Flowchart of patient inclusion

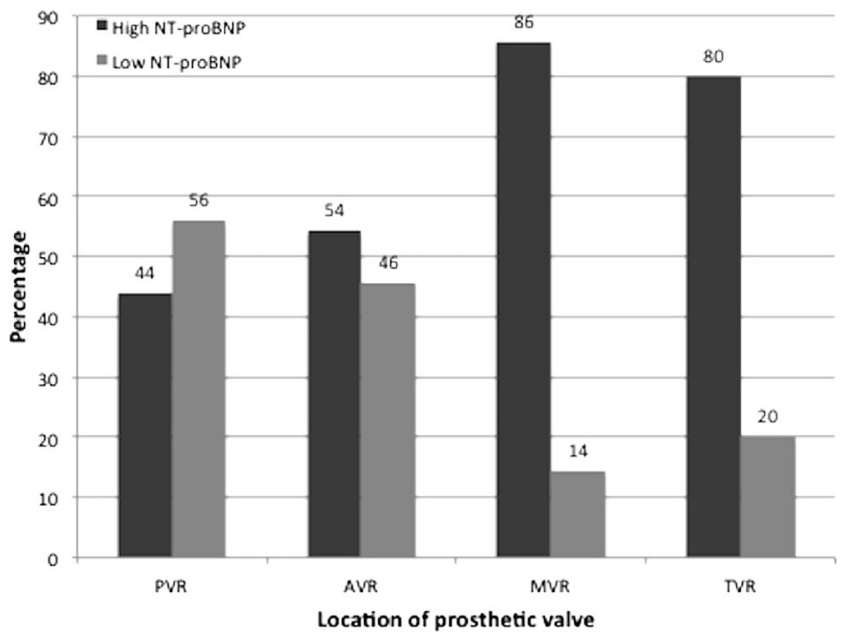

Fig. 2 NT-proBNP: percentages elevated NT-proBNP ( $\geq 125 \mathrm{pg} / \mathrm{ml})$ and low NT-proBNP $(<125 \mathrm{pg} / \mathrm{ml})$ in different valve locations; NT-proBNP N-terminal pro-brain natriuretic peptide, $\mathrm{pg} / \mathrm{ml}$

levels were elevated in a substantial but variable percentage (26-88\%) [5], reflecting the heterogeneous nature of this population. Therefore, to define its clinical utility, further research is warranted among specific subgroups.

Within the diverse population of CHD patients, valve replacement surgery is often inevitable [6]. Recently, Diller et al. [7]. demonstrated that especially those patients with a history of valve replacement surgery are at risk for HF. This may be related to the fact that prosthetic valves are often implanted during childhood or adolescence, resulting in a probably higher prevalence of prosthesis patient mismatch (PPM) than in non-congenital patients [8]. In addition, also a watchful waiting strategy to allow children and adolescents to grow further, in order to implant a larger prosthetic valve, may result in valve-related HF and deteriorating functional class [9]. To what extent NT-proBNP levels are of value for the clinical evaluation of ACHD pa- tients with a prosthetic valve is unclear. Therefore, the aim of this study was to investigate associations between NTproBNP and characteristics of valve prosthesis (including PPM), ventricular function and exercise capacity in ACHD patients with a prosthetic valve.

\section{Methods}

\section{Patient population}

In this multi-centre cross-sectional observational study, named PROSTheses in Adult congenital heart VAlve disease (acronym: PROSTAVA), ACHD patients were selected from the Dutch CONCOR registry [10]. The PROSTAVA study was conducted to investigate the relationship between characteristics of valve prostheses (type, labelled size, location) and functional outcome in ACHD patients. Study design and rationale were previously described [11]. Briefly, patients with a prosthetic heart valve (homografts, heterografts and mechanical valves in aortic, mitral, pulmonary or tricuspid position) registered in the CONCOR database and followed in one of the six PROSTAVA centres were eligible. Patients with multiple prosthetic valves or transposition of the great arteries with a systemic right ventricle, either congenitally corrected or after Mustard/ Senning correction, were excluded. The study was conducted in accordance with the Declaration of Helsinki and was approved by the institutional ethics committees.

\section{Collected data}

Collected data concerned demography and medical history, including previous cardiac surgical interventions, and were obtained by reviewing patient records. Prospective data were collected during routine clinical care: echocardiography, exercise testing and laboratory blood tests (including NT-proBNP and renal function).

\section{NT-proBNP}

Measurement of NT-proBNP was performed using the Elecsys proBNP ELISA (Roche Diagnostics, Mannheim, Germany). NT-proBNP was considered high when levels were $\geq 125 \mathrm{pg} / \mathrm{ml}$, based on the European Society of Cardiology guidelines for non-acute presentation of heart failure [12].

\section{Echocardiography}

Routine two-dimensional, M-mode and Doppler echocardiography were performed by experienced, board-certified sonographers and supervised by cardiologists of the partic- 
Table 1 Baseline characteristics

\begin{tabular}{|c|c|c|c|c|c|}
\hline & Total $(n=306)$ & $\operatorname{AVR}(n=141)$ & $\operatorname{PVR}(n=139)$ & $\operatorname{MVR}(n=21)$ & $\operatorname{TVR}(n=5)$ \\
\hline Male (\%) & $174(57)$ & $95(67)$ & $70(50)$ & $8(38)$ & $1(20)$ \\
\hline \multicolumn{6}{|l|}{ Diagnosis (\%) } \\
\hline Tetralogy of Fallot & - & - & 66 & - & - \\
\hline Pulmonary atresia & - & - & 12 & - & - \\
\hline Pulmonary valve stenosis & - & - & 12 & - & - \\
\hline Bicuspid aortic valve & - & 49 & - & - & - \\
\hline (Sub)valvular aortic stenosis & - & 25 & - & - & - \\
\hline Marfan syndrome & - & 19 & - & - & - \\
\hline AVSD & - & - & - & 48 & - \\
\hline Mitral stenosis & - & - & - & 19 & - \\
\hline Ebstein malformation & - & - & - & - & 100 \\
\hline Other & - & $7^{1}$ & $10^{2}$ & $33^{3}$ & - \\
\hline \multicolumn{6}{|c|}{ Indication for valve replacement (\%) } \\
\hline Regurgitation & - & 29 & 70 & 38 & 20 \\
\hline Stenosis & - & 21 & 13 & 14 & - \\
\hline Regurgitation and stenosis & - & 20 & 11 & 14 & - \\
\hline Other indications ${ }^{4}$ & - & 30 & 6 & 34 & 80 \\
\hline Age at first VR (y, SD) & $27 \pm 13$ & $30 \pm 11$ & $24 \pm 13$ & $25 \pm 17$ & $19 \pm 11$ \\
\hline Age at last VR (y, SD) & $30 \pm 12$ & $33 \pm 11$ & $26 \pm 11$ & $31 \pm 13$ & $29 \pm 13$ \\
\hline Time since last VR (y, SD) & $9 \pm 7$ & $11 \pm 8$ & $8 \pm 6$ & $10 \pm 6$ & $3 \pm 4$ \\
\hline \multicolumn{6}{|c|}{ Number of valve replacements (\%) } \\
\hline 1 & $232(76)$ & $105(74)$ & $114(82)$ & $12(57)$ & $1(20)$ \\
\hline 2 & $59(19)$ & $29(21)$ & $19(14)$ & $8(38)$ & $3(60)$ \\
\hline 3 & $14(5)$ & $6(4)$ & $6(4)$ & $1(5)$ & $1(20)$ \\
\hline 4 & $1(0)$ & $1(1)$ & $0(0)$ & $0(0)$ & $0(0)$ \\
\hline \multicolumn{6}{|l|}{ Valve type (\%) } \\
\hline Biological & $133(43)$ & $15(11)$ & $114(82)$ & $1(5)$ & $3(60)$ \\
\hline Bio conduit & $5(4)$ & $0(0)$ & $5(4)$ & $0(0)$ & $0(0)$ \\
\hline Bio stented & $111(83)$ & $7(47)$ & $101(73)$ & $1(100)$ & $2(67)$ \\
\hline Bio stentless & $11(8)$ & $8(53)$ & $3(2)$ & $0(0)$ & $0(0)$ \\
\hline Transcatheter & $7(5)$ & $0(0)$ & $6(4)$ & $0(0)$ & $1(33)$ \\
\hline Mechanical & $170(56)$ & $126(89)$ & $22(16)$ & $20(95)$ & $2(40)$ \\
\hline Bi-leaflet & $154(90)$ & $113(90)$ & $22(100)$ & $17(85)$ & $2(100)$ \\
\hline Mono-leaflet & $16(9)$ & $13(10)$ & $0(0)$ & $3(15)$ & $0(0)$ \\
\hline Valve size & $25 \pm 3$ & $23 \pm 3$ & $25 \pm 2$ & $29 \pm 3$ & $31 \pm 4$ \\
\hline Age (y, SD) & $39 \pm 11$ & $44 \pm 11$ & $35 \pm 10$ & $41 \pm 13$ & $32 \pm 13$ \\
\hline Body surface area (SD) & $1.95 \pm 0.2$ & $1.99 \pm 0.2$ & $1.92 \pm 0.2$ & $1.87 \pm 0.2$ & $1.87 \pm 0.3$ \\
\hline BMI (SD) & $24.7 \pm 4$ & $25.1 \pm 4$ & $24.2 \pm 4$ & $24.7 \pm 4$ & $27.5 \pm 4$ \\
\hline
\end{tabular}


Table 1 Baseline characteristics (Continued)

\begin{tabular}{|c|c|c|c|c|c|}
\hline & Total $(n=306)$ & $\operatorname{AVR}(n=141)$ & $\operatorname{PVR}(n=139)$ & $\operatorname{MVR}(n=21)$ & TVR $(n=5)$ \\
\hline \multicolumn{6}{|l|}{ NYHA (\%) } \\
\hline I & $148(48)$ & $82(58)$ & $65(47)$ & $1(5)$ & $0(0)$ \\
\hline II & $86(28)$ & $41(29)$ & $42(30)$ & $3(14)$ & $0(0)$ \\
\hline III & $42(14)$ & $10(7)$ & $12(9)$ & $15(71)$ & $5(100)$ \\
\hline IV & $4(1)$ & $0(0)$ & $2(1)$ & $2(10)$ & $0(0)$ \\
\hline Unknown & $26(9)$ & $8(6)$ & $18(13)$ & $0(0)$ & $0(0)$ \\
\hline
\end{tabular}

${ }^{1}$ Truncus arteriosus (2.9); atrial septal defect + D.B. (0.7); ventricular septal defect (VSD) (0.7); double outlet right ventricle (DORV) Fallot (0.7); DORV transposition of the great arteries (TGA) (0.7); TGA + pulmonary stenosis + VSD (2.2); empty cells (2.2).

${ }^{2} \mathrm{VSD}+$ coarctation (3.6); TGA (1.4); PA + VSD (0.7).

${ }^{3}$ Anomalous left coronary artery arising from the pulmonary artery (ALCAPA) (4.8); ASD (21.3); DORV + coarctation (4.8); Marfan (4.8); bicuspid aortic valve + coarctation (4.8).

${ }^{4}$ Other indications include valve atresia, aorta dissection, aortic dilatation, endocarditis and valve complications. Values are mean/median \pm standard deviation (SD); $A V R$ aortic valve replacement, $P V R$ pulmonary valve replacement, $M V R$ mitral valve replacement, $T V R$ tricuspid valve replacement, $V R$ valve replacement, $A V S D$ atrioventricular septal defect, $V S D$ ventricular septal defect, $T G A$ transposition of the great arteries, $P A$ patent arteriosus, ToF Tetralogy of Fallot, ASD atrial septal defect, DORV (Fallot) double outlet right ventricle (ToF), ALCAPA anomalous left coronary artery arising from the pulmonary artery, NYHA New York Heart Association, $y$ years.

Table 2 Echocardiography, exercise capacity and NT-proBNP

\begin{tabular}{|c|c|c|c|c|c|c|}
\hline \multirow[t]{2}{*}{ Method } & Variable & Total & AVR & PVR & MVR & TVR \\
\hline & $n(\%)$ & $306(100)$ & $141(46)$ & $139(45)$ & $21(7)$ & $5(2)$ \\
\hline \multirow[t]{8}{*}{ Echocardiography } & $\operatorname{LVEF}(\%)$ & $55 \pm 8$ & $57 \pm 9$ & $55 \pm 6$ & $50 \pm 11$ & - \\
\hline & LVEF $\geq 50 \%(n, \%)$ & $108(77)$ & $35(78)$ & $70(78)$ & $3(60)$ & - \\
\hline & LVEDD (mm) & $50 \pm 8$ & $50 \pm 7$ & $49 \pm 8$ & $53 \pm 10$ & $48 \pm 7$ \\
\hline & $\operatorname{LVESD}(\mathrm{mm})$ & $34 \pm 8$ & $33 \pm 7$ & $34 \pm 7$ & $41 \pm 9$ & $28 \pm 7$ \\
\hline & LV mass ( $\left.\mathrm{g} / \mathrm{m}^{2} \mathrm{BSA}\right)$ & $97 \pm 33$ & $98 \pm 29$ & $60 \pm 54$ & $112 \pm 40$ & $80 \pm 28$ \\
\hline & TAPSE (mm) & $17 \pm 4$ & $17 \pm 4$ & $17 \pm 4$ & $18 \pm 3$ & $15 \pm 3$ \\
\hline & TAPSE $\geq 17 \mathrm{~mm}(n, \%)$ & $150(56)$ & $59(54)$ & $75(57)$ & $14(70)$ & $2(40)$ \\
\hline & $\operatorname{EOA}\left(\mathrm{cm}^{2} / \mathrm{m}^{2}\right)$ & $2.1 \pm 1$ & $1.9 \pm 1$ & $2.4 \pm 2$ & $2.4 \pm 1$ & 4.9 \\
\hline \multirow[t]{3}{*}{ Exercise testing } & $\mathrm{VO}_{2}$ peak $(\mathrm{ml} / \mathrm{min} / \mathrm{kg})$ & $27 \pm 8$ & $29 \pm 8$ & $28 \pm 7$ & $22 \pm 7$ & $19 \pm 6$ \\
\hline & $\operatorname{PPEC}(\%)$ & $81 \pm 23$ & $84 \pm 24$ & $76 \pm 19$ & $72 \pm 25$ & $71 \pm 34$ \\
\hline & PPEC $\leq 75 \%(n, \%)$ & $94(41)$ & $32(31)$ & $48(47)$ & $12(67)$ & $2(50)$ \\
\hline \multirow[t]{2}{*}{ Laboratory blood } & NT-proBNP & $140 \pm 329$ & $146 \pm 374$ & $108 \pm 253$ & $316 \pm 372$ & $247 \pm 300$ \\
\hline & $\%$ High NT-proBNP & 52 & 54 & 44 & 86 & 80 \\
\hline
\end{tabular}

Values are mean or median \pm SD or $n$. $L V E F$ left ventricular ejection fraction, $L V E D D$ left ventricular end-diastolic diameter, $L V E S D$ left ventricular end-systolic diameter, $R V E F$ right ventricular ejection fraction, TAPSE tricuspid annular plane systolic excursion, EOA effective orifice area, PPEC percentage of predicted exercise capacity, NT-proBNP N-terminal pro-brain natriuretic peptide, pg/ml (cut-off for high NT-proBNP $\geq 125 \mathrm{pg} / \mathrm{ml})$

ipating hospital. Both the images and reports were sent to the University Medical Center Groningen, where the echocardiograms were blinded. Measurements related to the prosthetic valve were independently re-assessed and subsequently checked by senior investigators.

Other measurements concerning ventricular size and function and native valve morphology and function were collected from the original echo reports. Left ventricular ejection fraction (LVEF) was measured using Simpson's rule or, when image quality was suboptimal, using visual estimation. Right ventricular function was assessed with tricuspid annular plane systolic excursion (TAPSE). Prosthetic valvar effective orifice area (EOA in $\mathrm{cm}^{2}$ ) was calculated using the continuity equation [13]. EOA was indexed for body surface area (iEOA). For aortic valve replacement (AVR) patients, PPM was classified as moderate PPM (iEOA $0.85-0.65 \mathrm{~cm}^{2} / \mathrm{m}^{2}$ ) and as severe PPM (iEOA $<0.65 \mathrm{~cm}^{2} / \mathrm{m}^{2}$ ) [8]. The native pulmonary EOA in adults is about $30 \%$ larger than the aortic EOA [14]. We therefore assumed cut-off values for PPM in pulmonary valve replacement (PVR) patients accordingly (moderate PPM was defined as iEOA $\leq 1.10 \mathrm{~cm}^{2} / \mathrm{m}^{2}$ and severe PPM as $\mathrm{iEOA} \leq 0.85 \mathrm{~cm}^{2} / \mathrm{m}^{2}$ ).

\section{Exercise capacity testing}

Exercise capacity was measured using a bicycle or treadmill ergometer, assessing either peak oxygen uptake $\left(\mathrm{VO}_{2}\right.$ peak, 
Table 3 Univariable and multivariable parameters associated with NT-proBNP for all patients (cut-off $125 \mathrm{pg} / \mathrm{ml}$ )

\begin{tabular}{|c|c|c|c|c|}
\hline & Univariate & & Multivariate & \\
\hline & All & & All & \\
\hline Variable & $95 \% \mathrm{CI}(\mathrm{B})$ & $p$ & $95 \% \mathrm{CI}(\mathrm{B})$ & $p$ \\
\hline $\operatorname{BSA}\left(\mathrm{m}^{2}\right)$ & -0.50 to 0.07 & 0.141 & - & - \\
\hline BMI $\left(\mathrm{kg} / \mathrm{m}^{2}\right)$ & -0.01 to 0.02 & 0.545 & - & - \\
\hline Gender & -0.41 to -0.15 & $>0.001$ & -0.34 to -0.02 & 0.029 \\
\hline Age & 0.01 to 0.02 & $>0.001$ & -0.01 to 0.02 & 0.310 \\
\hline NYHA class & -0.01 to 0.16 & 0.077 & -0.08 to 0.11 & 0.804 \\
\hline Age at first VR (y) & 0.00 to 0.01 & 0.164 & - & - \\
\hline Age at last VR (y) & 0.00 to 0.01 & 0.020 & -0.02 to 0.01 & $0.295^{*}$ \\
\hline Time since last VR (y) & 0.00 to 0.02 & 0.093 & - & - \\
\hline Valve size $(\mathrm{mm})$ & 0.01 to 0.03 & 0.434 & - & - \\
\hline Valve type (bio/mech) & 0.00 to 0.27 & 0.055 & -0.07 to 0.25 & 0.257 \\
\hline $\mathrm{iEOA}\left(\mathrm{cm}^{2} / \mathrm{m}^{2}\right)$ & -0.18 to 0.12 & 0.689 & - & - \\
\hline $\mathrm{PPM}\left(\mathrm{iEOA} \leq 0.85 \mathrm{~cm}^{2} / \mathrm{m}^{2}\right)$ & -0.21 to 0.11 & 0.520 & - & - \\
\hline Indexed LV mass $\left(\mathrm{g} / \mathrm{m}^{2}\right)$ & 0.00 to 0.00 & 0.313 & - & - \\
\hline $\operatorname{LVEF}(\%)$ & -0.01 to 0.01 & 0.939 & - & - \\
\hline LVEDD (mm) & -0.01 to 0.01 & 0.402 & - & - \\
\hline LVESD (mm) & 0.00 to 0.02 & 0.184 & - & - \\
\hline $\operatorname{RVEF}(\%)$ & -0.01 to 0.02 & 0.371 & - & - \\
\hline TAPSE (mm) & -0.02 to 0.02 & 0.808 & - & - \\
\hline Renal function (ml/min) & -0.01 to 0.00 & 0.022 & -0.01 to 0.00 & 0.107 \\
\hline $\mathrm{VO}_{2} \max (\mathrm{ml} / \mathrm{min} / \mathrm{kg})$ & -0.03 to -0.02 & $<0.001$ & -0.03 to -0.01 & $<0.001$ \\
\hline $\operatorname{PPEC}(\%)$ & -0.01 to 0.00 & 0.113 & - & - \\
\hline
\end{tabular}

$C I$ confidence interval, $B S A$ body surface area, $B M I$ body mass index, $V R$ valve replacement, $i E O A$ indexed effective orifice area, $P P M$ patient prosthesis mismatch, $L V E F$ left ventricular ejection fraction, $L V E D D$ left ventricular end-diastolic diameter, $L V E S D$ left ventricular end-systolic diameter, RVEF right ventricular ejection fraction, TAPSE tricuspid annular plane systolic excursion, PPEC percentage of predicted exercise capacity, $n p$ not performed. Bold text: univariable parameters with a $p$-value $<0.1$ are used in multivariate regression analysis. ${ }^{*}$ Collinearity of Statistics is reported between the variables 'age at last VR' and 'time since last VR'

$\mathrm{ml} / \mathrm{min} / \mathrm{kg}$ ) or maximum workload (Wpeak, Watts). The predicted peak oxygen uptake $\left(\mathrm{VO}_{2}\right.$ pred) and workload (Wpred) was calculated as previously described $[15,16]$.

Exercise capacity testing was performed uniformly and reproducible among the different centres and started with a short warm-up (without load), followed by a stepwise increase of workload consistent with a protocol based on sex, age, height and weight. Exercise duration was aimed for at least 6-8 minutes. The percentage of predicted exercise capacity (PPEC) was calculated by dividing the achieved exercise level $\left(\mathrm{VO}_{2}\right.$ peak or Wpeak) by the predicted exercise level $\left(\mathrm{VO}_{2}\right.$ pred or Wpred). A PPEC $\leq 75 \%$ was considered a decreased exercise capacity [17].

\section{Statistics}

Data were analysed using SPSS ${ }^{\circledR}$ Statistics version 22.0. Descriptive statistics were calculated as mean values and standard deviations for normally distributed continuous variables, medians and quartiles for continuous variables with non-normal distribution and absolute numbers and percentages for dichotomous variables. Comparisons of continuous variables between groups were made by unpaired Student's t-tests or the Mann-Whitney U test, depending on their distribution, and dichotomous variables were compared using the $\chi^{2}$ or Fisher's exact test. Univariable and multivariable regression analysis (dependent variable: NT-proBNP) was used to study the association between NT-proBNP and prosthetic valve characteristics or functional capacity. All independent covariates with $p<0.10$ in univariable regression analyses were included in multivariable regression analysis. A two-sided $p$-value $<0.05$ was considered statistically significant. Due to the limited number of patients with mitral valve replacement (MVR) and tricuspid valve replacement (TVR), regression analyses were confined to AVR and PVR patients.

\section{Results}

A flowchart for patient selection with exclusion criteria is shown in Fig. 1. The study population comprised 141 AVR patients, 139 PVR patients, 21 MVR patients and 5 TVR patients. Baseline characteristics are presented in Table 1. 


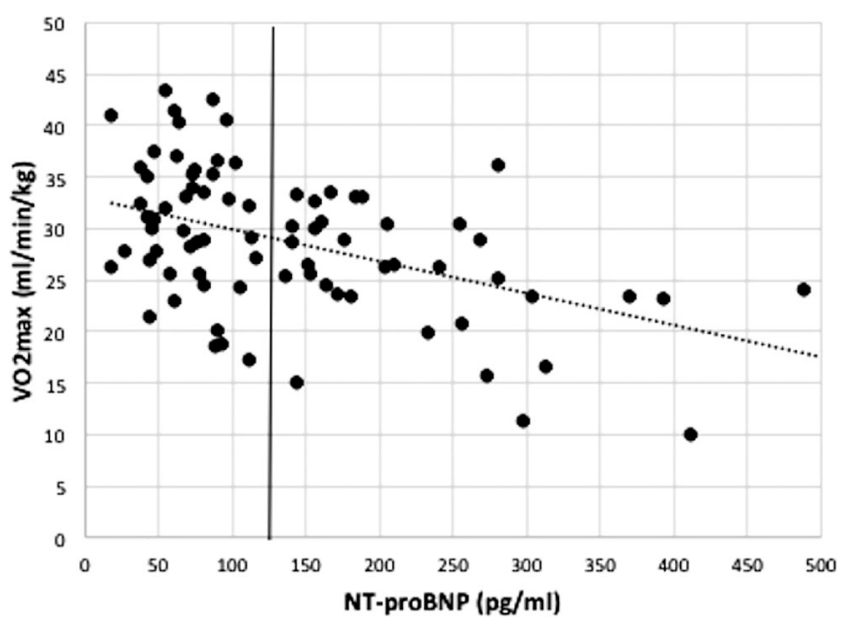

Fig. 3 Association between NT-proBNP (cut-off $125 \mathrm{pg} / \mathrm{ml}$ ) and $\mathrm{VO}_{2}$ peak in PVR patients; NT-proBNP $\mathrm{N}$-terminal pro-brain natriuretic peptide, $\mathrm{pg} / \mathrm{ml}$ (cut-off for high NT-proBNP $\geq 125 \mathrm{pg} / \mathrm{ml}$ ), $P V R$ pulmonary valve replacement. Dotted line indicates cut-off for elevated NT-proBNP levels $(125 \mathrm{pg} / \mathrm{ml})$. Pearson's $\mathrm{r}=-0.555, p<$ $0.001, \mathrm{y}=33-0.03 * \mathrm{x}$

The majority were male (57\%). The main diagnosis in PVR patients was Tetralogy of Fallot (ToF, 66\%) and in AVR patients bicuspid aortic valve (49\%).

Mean age at surgery for first and latest valve replacement was $27 \pm 13$ (range $0-51$ ) and $30 \pm 12$ years (range 3-67), respectively. The valve type differed between AVR and PVR patients: $89 \%$ of AVR were mechanical valves while in PVR $82 \%$ of the patients had biological valves implanted $(p<0.001)$. The majority of patients were in NYHA class I-II at inclusion (76\%). NYHA class was significantly higher in MVR patients compared with PVR and AVR patients $(p<0.001)$. Age at first and last valve replacement was significantly higher in AVR patients compared with PVR patients $(p<0.001)$.

\section{NT-proBNP}

The median NT-proBNP level in the total study population was 140 (range 13-3132) pg/ml (Table 2). Patients with higher NT-proBNP levels were more likely to be women (median level 183 and $104 \mathrm{pg} / \mathrm{ml}$ in women and men, respectively, $p<0.001)$ and older $(p<0.001)$. For the whole study sample, higher age at latest valve replacement was significantly associated with higher NT-proBNP levels $(p=0.02)$. Median NT-proBNP level in AVR patients was $146 \mathrm{pg} / \mathrm{ml}$, compared with $108 \mathrm{pg} / \mathrm{ml}$ in PVR patients $(p=$ $\mathrm{ns})$. The highest NT-proBNP levels were seen in MVR patients (median $316 \mathrm{pg} / \mathrm{ml} ; p<0.001$ and $p=0.002 \mathrm{com}$ pared with PVR and AVR, respectively). High NT-proBNP levels $(\geq 125 \mathrm{pg} / \mathrm{ml})$ were found in $44 \%$ of the PVR patients, $54 \%$ of the AVR patients, and 86 and $80 \%$ of the MVR and TVR patients, respectively (Fig. 2).

\section{Echocardiography and exercise testing}

Echocardiographic characteristics of the entire study population and for each separate prosthetic valve location are displayed in Table 2. Normal LVEF was found in $78 \%$ of the AVR patients and $78 \%$ of the PVR patients. Left ventricular (LV) mass was higher in AVR in comparison with PVR patients $(p=0.015)$.

A normal right ventricular function (TAPSE $\geq 17 \mathrm{~mm}$ ) was found in $56.4 \%(n=150)$ of all patients, including $57.3 \%$ of PVR patients $(n=75)$ and $53.6 \%$ of AVR patients $(n=59)$. The effective orifice area (EOA) of the pulmonary valves was significantly larger than aortic prosthetic valves (Table 2, $p=0.003$ ). PPM was found in $50 \%$ of the PVR patients and $48 \%$ of the AVR patients.

Exercise capacity was assessed in 228 patients $(75 \%)$, with $194 \mathrm{VO}_{2} \max$ tests $(85 \%)$ and 34 ergometric tests (15\%). In all patients, the median PPEC was $81 \%$ (IQR 65-98\%) and $41 \%$ had impaired exercise capacity (PPEC $\leq 75 \%$, Table 2). Decreased PPEC was observed in $31 \%$ of the AVR patients, compared with $47 \%$ of the PVR patients $(p=0.017) . \mathrm{VO}_{2}$ peak was significantly lower in MVR compared with AVR $(p=0.001)$ and PVR patients $(p<0.001)$.

\section{Associations with high NT-proBNP levels ( $\geq 125$ pg/ml)}

For the entire study population, gender $(p<0.001)$, age $(p<0.001)$, age at last valve replacement $(p=0.020)$, renal function $(p=0.022)$ and $\mathrm{VO}_{2} \max (p<0.001)$ were associated with NT-proBNP $(p<0.05)$. Gender $(p=0.029)$ and $\mathrm{VO}_{2} \max (p<0.001)$ were associated with NT-proBNP in multivariate analysis as well (Table 3).

In the PVR group, univariable parameters associated with NT-proBNP $(p<0.1)$ included age at valve replacement surgery $(p=0.091)$ and $\mathrm{VO}_{2}$ peak $(p<0.001)$ (Table 4; Fig. 3). In a multivariate model, a higher NT-proBNP level remained significantly associated with a lower $\mathrm{VO}_{2}$ peak, even after adjustment for age, gender and age at valve replacement surgery $(p=0.015)$, as presented in Table 4 . PPEC was negatively associated with NT-proBNP as well $(p=0.025$ in PVR) when corrected for the same variables.

In AVR patients, $\mathrm{VO}_{2}$ peak was negatively associated with NT-proBNP as well, although in a multivariable model, including age, gender and renal function, only gender remained significantly associated with NT-proBNP $(p=0.034$, Table 4).

\section{Discussion}

This multi-centre cross-sectional study focused on the value of NT-proBNP in ACHD and a prosthetic valve. Using the European Society of Cardiology cut-off for chronic HF 


\section{Advertisement placed here.}

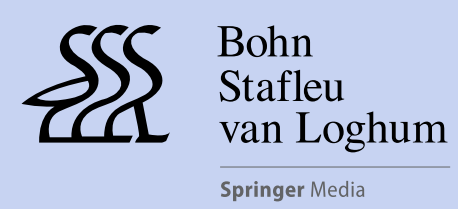

Houten 2016 


\section{Advertisement placed here.}

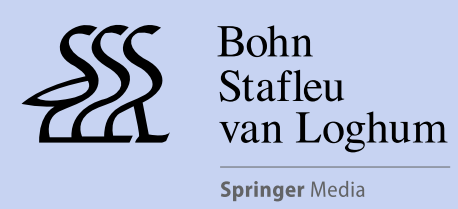

Houten 2016 


\section{Advertisement placed here.}

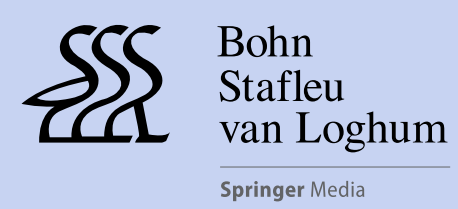

Houten 2016 


\section{Advertisement placed here.}

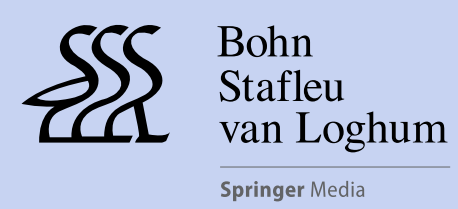

Houten 2016 
Table 4 Univariable and multivariable parameters associated with NT-proBNP for PVR and AVR patients (cut-off $125 \mathrm{pg} / \mathrm{ml}$ )

\begin{tabular}{|c|c|c|c|c|c|c|c|c|}
\hline & Univariate & & & & Multivariate & & & \\
\hline & PVR & & AVR & & PVR & & AVR & \\
\hline Variable & $95 \% \mathrm{CI}(\mathrm{B})$ & $P$ & $95 \% \mathrm{CI}(\mathrm{B})$ & $P$ & $95 \% \mathrm{CI}(\mathrm{B})$ & $P$ & $95 \% \mathrm{CI}(\mathrm{B})$ & $P$ \\
\hline $\operatorname{BSA}\left(\mathrm{m}^{2}\right)$ & -0.59 to 0.27 & 0.460 & -0.76 to 0.10 & 0.128 & - & - & - & - \\
\hline BMI $\left(\mathrm{kg} / \mathrm{m}^{2}\right)$ & -0.02 to 0.02 & 0.990 & -0.03 to 0.03 & 0.877 & - & - & - & - \\
\hline Gender & $\begin{array}{l}-0.47 \text { to } \\
-0.08\end{array}$ & 0.007 & $\begin{array}{l}-0.52 \text { to } \\
-0.14\end{array}$ & 0.001 & $\begin{array}{l}-0.43 \text { to } \\
-0.01\end{array}$ & 0.045 & $\begin{array}{l}-0.57 \text { to } \\
-0.02\end{array}$ & 0.034 \\
\hline Age & 0.01 to 0.03 & 0.004 & 0.00 to 0.02 & 0.047 & -0.00 to 0.05 & 0.098 & -0.01 to 0.01 & 0.951 \\
\hline NYHA class & -0.10 to 0.18 & 0.582 & -0.13 to 0.18 & 0.769 & - & - & - & - \\
\hline Age at first VR (y) & -0.00 to 0.01 & 0.119 & -0.01 to 0.01 & 0.710 & - & - & - & - \\
\hline Age at last VR (y) & -0.00 to 0.02 & 0.091 & -0.00 to 0.01 & 0.247 & -0.03 to 0.01 & 0.251 & - & - \\
\hline $\begin{array}{l}\text { Time since last VR } \\
\text { (y) }\end{array}$ & -0.01 to 0.03 & 0.174 & -0.01 to 0.02 & 0.258 & - & - & - & - \\
\hline Valve size $(\mathrm{mm})$ & -0.04 to 0.05 & 0.811 & -0.06 to 0.01 & 0.172 & - & - & - & - \\
\hline $\begin{array}{l}\text { Valve type (bio/ } \\
\text { mech) }\end{array}$ & -0.15 to 0.36 & 0.397 & -0.32 to 0.41 & 0.802 & - & - & - & - \\
\hline $\mathrm{iEOA}\left(\mathrm{cm}^{2} / \mathrm{m}^{2}\right)$ & -0.22 to 0.19 & 0.882 & -0.37 to 0.19 & 0.523 & - & - & - & - \\
\hline $\begin{array}{l}\text { PPM }(\mathrm{iEOA} \\
\left.\leq 0.85 \mathrm{~cm}^{2} / \mathrm{m}^{2}\right)\end{array}$ & -0.10 to 0.44 & 0.204 & -0.23 to 0.18 & 0.816 & - & - & - & - \\
\hline $\begin{array}{l}\text { Indexed LV mass } \\
\left(\mathrm{g} / \mathrm{m}^{2}\right)\end{array}$ & $\mathrm{Np}$ & $\mathrm{Np}$ & -0.00 to 0.01 & 0.217 & - & - & - & - \\
\hline $\operatorname{LVEF}(\%)$ & -0.01 to 0.02 & 0.503 & -0.03 to 0.01 & 0.440 & - & - & - & - \\
\hline LVEDD (mm) & -0.03 to 0.01 & 0.217 & -0.01 to 0.02 & 0.250 & - & - & - & - \\
\hline LVESD (mm) & -0.02 to 0.02 & 0.735 & -0.01 to 0.02 & 0.421 & - & - & - & - \\
\hline RVEF (\%) & -0.01 to 0.02 & 0.666 & -0.01 to 0.02 & 0.641 & - & - & - & - \\
\hline TAPSE (mm) & -0.03 to 0.02 & 0.859 & -0.03 to 0.03 & 0.912 & - & - & - & - \\
\hline $\begin{array}{l}\text { Renal function } \\
(\mathrm{ml} / \mathrm{min})\end{array}$ & -0.01 to 0.00 & 0.248 & $\begin{array}{l}-0.01 \text { to } \\
-0.00\end{array}$ & 0.009 & - & - & -0.01 to 0.00 & 0.087 \\
\hline $\begin{array}{l}\mathrm{VO}_{2} \max \\
(\mathrm{ml} / \mathrm{min} / \mathrm{kg})\end{array}$ & $\begin{array}{l}-0.04 \text { to } \\
-0.02\end{array}$ & $<0.001$ & $\begin{array}{l}-0.03 \text { to } \\
-0.00\end{array}$ & 0.042 & $\begin{array}{l}-0.04 \text { to } \\
-0.00\end{array}$ & 0.015 & -0.02 to 0.01 & 0.698 \\
\hline $\operatorname{PPEC}(\%)$ & -0.01 to 0.00 & 0.245 & -0.01 to 0.00 & 0.922 & - & - & - & - \\
\hline
\end{tabular}

$A V R$ aortic valve replacement, $P V R$ pulmonary valve replacement, $C I$ confidence interval, $B S A$ body surface area, $B M I$ body mass index, $V R$ valve replacement, $i E O A$ indexed effective orifice area, $P P M$ patient prosthesis mismatch, $L V E F$ left ventricular ejection fraction, $L V E D D$ left ventricular end-diastolic diameter, $L V E S D$ left ventricular end-systolic diameter, RVEF right ventricular ejection fraction, TAPSE tricuspid annular plane systolic excursion, PPEC percentage of predicted exercise capacity, $n p$ not performed. Bold text: univariable parameters with a $p$-value $<0.1$ are used in multivariate regression analysis

of $125 \mathrm{pg} / \mathrm{ml}$, elevated NT-proBNP levels were found in more than $50 \%$ of the patients. In PVR patients, high NT-proBNP levels were associated with decreased exercise capacity.

\section{NT-proBNP in CHD}

The high percentage of elevated NT-proBNP levels in PVR patients and AVR patients (44 and 54\%, respectively) is remarkable. In a smaller subgroup of patients with an atrioventricular prosthetic valve, this percentage was even higher (i.e. $86 \%$ for MVR and $80 \%$ for TVR patients). The high percentages of elevated NT-proBNP levels in our ACHD population are comparable to, for example, populations with stable chronic kidney disease (127 vs. 140 pg/ml in this population) [18], but not as high as recently re- ported in a population with HF with preserved ejection fraction (median $1772 \mathrm{pg} / \mathrm{ml}$ ) [19]. For ACHD patients, Eindhoven et al. found comparable percentages of elevated NT-proBNP levels in both a heterogeneous group with various ACHD patients [5] and in adult patients with corrected ToF (53 and $55 \%$, respectively) [20]. However, in their study population with various CHD lesions, patients with systemic right ventricular and Fontan circulation mainly contributed to the elevated NT-proBNP levels. In our study, these patients were excluded.

The higher NT-proBNP levels found in AVR patients compared with PVR patients (146 vs. $108 \mathrm{pg} / \mathrm{ml}$, respectively) could possibly be explained by the higher LV mass found in AVR patients $(p=0.015)$. The study by Mishra et al. [18]. in patients with chronic kidney disease describes the association between high NT-proBNP levels and 
higher LV mass. However, this association between high NT-proBNP levels and LV mass in AVR patients did not hold true in the regression analysis.

Whether the high percentages of elevated NT-proBNP in our study cohort are related to surgical technique, prosthetic valve material, (subclinical) heart failure or the timing of valve surgery could not be answered by this study. Serial measurements could shed light on this interesting question.

\section{Associations with high NT-proBNP levels ( $\geq 125 \mathrm{pg} / \mathrm{ml})$}

In line with other studies, NT-proBNP levels were higher in women and associated with ageing [21]. This finding highlights the need for sex- and age-specific reference values of NT-proBNP to be useful for diagnostic purposes.

Although NT-proBNP levels tended to be related to the age at last valve replacement, indicating that higher age at last valve replacement may possibly result in higher NTproBNP levels at adult age, this association did not hold true after adjustment for sex and age. At least in our population, this may indicate that high pro-BNP levels are not a reflection of a late valve replacement. Given the relationship between ventricular dysfunction and HF, it may be anticipated that ventricular function is associated with NTproBNP levels. Yet, we did not find such a relationship. However, diastolic characteristics (not taken into account in our study) are also of importance in the release of NTproBNP, as recently described for a CHD population [22]. Although we previously found an association between PPM and exercise capacity in AVR patients [23], this did not translate into higher NT-proBNP levels in this subgroup. At least for AVR patients, a possible explanation could be the rather preserved left ventricular systolic function (mean LVEF $57 \%$ ).

\section{NT-proBNP and exercise capacity in PVR patients}

We found an association between NT-proBNP and exercise capacity in PVR patients: a higher NT-proBNP level was associated with a lower $\mathrm{VO}_{2}$ peak. This result is in line with the findings in patients with various CHD lesions (with or without prosthetic valve) of Eindhoven et al. [5]. Of note, Eindhoven et al. could not establish this association in their population of adult ToF patients [20]; however in their study only $55 \%$ of the ToF patients had a prosthetic valve, whereas our findings were most profound in PVR patients, of which $66 \%$ were diagnosed with ToF. Our results are in line with those of Norozi et al. who found a correlation between exercise capacity and NT-proBNP in ToF patients, also showing comparable NT-proBNP levels as found in our study [24]. Our findings strengthen the use of NT-proBNP as possible marker of functional capacity in PVR patients. Although right ventricular function is an important determinant of exercise performance [25], we could not confirm significant associations between NTproBNP and TAPSE. However, one has to keep in mind that TAPSE reflects only longitudinal right ventricular contraction, whereas radial contraction may be preserved or even enhanced postoperatively. This finding is reinforced by the fact that in AVR patients TAPSE was decreased in a similar proportion ( $46 \%$ vs. $43 \%$ in PVR patients, $p=n s$ ).

\section{Limitations}

The multiple types and locations of the prosthetic valves in combination with the underlying cardiac malformation resulted in a heterogeneous population. We chose to analyse our data separately for each valve location. Therefore, the study results that were found in PVR patients could not be extrapolated to patients with another located prosthetic valve (or vice versa). Finally, due to the limited number of patients, MVR and TVR patients were not included in the regression analysis.

\section{Conclusion}

NT-proBNP levels are elevated in more than $50 \%$ of the ACHD population with a prosthetic valve. Higher NTproBNP levels are strongly associated with poor exercise capacity in PVR patients. Further, prospective studies of NT-proBNP values in CHD patients are necessary in order to assess its predictive value for prognosis in these patients.

Funding A grant from the Netherlands Heart Foundation to P.G.P. supported this work (2009B013).

Conflict of interest R. C. Schoonbeek, P. G. Pieper, Y. J. van Slooten, H. G. Freling, G. T. Sieswerda, A. P. J. van Dijk, M. R. M. Jongbloed, M. C. Post, B. J. Bouma, R. M. F. Berger, T. Ebels and J. P. van Melle state that they have no competing interest.

Open Access This article is distributed under the terms of the Creative Commons Attribution 4.0 International License (http:// creativecommons.org/licenses/by/4.0/), which permits unrestricted use, distribution, and reproduction in any medium, provided you give appropriate credit to the original author(s) and the source, provide a link to the Creative Commons license, and indicate if changes were made.

\section{References}

1. van Veldhuisen DJ, Linssen GC, Jaarsma T, et al. B-type natriuretic peptide and prognosis in heart failure patients with preserved and reduced ejection fraction. J Am Coll Cardiol. 2013;61:1498-506.

2. Scrutinio D, Ammirati E, Guida P, et al. Clinical utility of N-terminal pro-B-type natriuretic peptide for risk stratification of patients with acute decompensated heart failure. Derivation and 
validation of the ADHF/NT-proBNP risk score. Int J Cardiol. 2013;168:2120-6.

3. Oremus M, Don-Wauchope A, McKelvie R, et al. BNP and NTproBNP as prognostic markers in persons with chronic stable heart failure. Heart Fail Rev. 2014;19:471-505.

4. Melina G, Angeloni E, Benedetto U, et al. Relationship between prosthesis patient mismatch and pro-brain natriuretic peptides after aortic valve replacement. J Heart Valve Dis. 2010;19:171-6.

5. Eindhoven JA, van den Bosch AE, Ruys TP, et al. N-terminal proB-type natriuretic peptide and its relationship with cardiac function in adults with congenital heart disease. J Am Coll Cardiol. 2013;62:1203-12.

6. van der Linde D, Konings EE, Slager MA, et al. Birth prevalence of congenital heart disease worldwide: a systematic review and metaanalysis. J Am Coll Cardiol. 2011;58:2241-7.

7. Diller GP, Kempny A, Alonso-Gonzalez R, et al. Survival prospects and circumstances of death in contemporary adult congenital heart disease patients under follow-up at a large tertiary centre. Circulation. 2015;132:2118-25.

8. Pibarot P, Dumesnil JG, Cartier PC, Metras J, Lemieux MD. Patient-prosthesis mismatch can be predicted at the time of operation. Ann Thorac Surg. 2001;71(5 Suppl):265-8.

9. O’Byrne ML, Glatz AC, Mercer-Rosa L, Gillespie MJ, Dori Y, Goldmuntz E, et al. Trends in pulmonary valve replacement in children and adults with tetralogy of fallot. Am J Cardiol. 2015;115:118-24.

10. van der Velde ET, Vriend JW, Mannens MM, Uiterwaal CS, Brand $\mathrm{R}$, Mulder BJ. CONCOR, an initiative towards a national registry and DNA-bank of patients with congenital heart disease in the Netherlands: rationale, design, and first results. Eur J Epidemiol. 2005;20:549-57.

11. Freling HG, van Slooten YJ, van Melle JP, et al. Prosthetic valves in adult patients with congenital heart disease: rationale and design of the Dutch PROSTAVA study. Neth Heart J. 2012;20:419-24.

12. McMurray JJ, Adamopoulos S, Anker SD, et al. ESC guidelines for the diagnosis and treatment of acute and chronic heart failure 2012: the task force for the diagnosis and treatment of acute and chronic heart failure 2012 of the European Society of Cardiology. Developed in collaboration with the Heart Failure Association (HFA) of the ESC. Eur J Heart Fail. 2012;14:803-69.

13. Zoghbi WA, Chambers JB, Dumesnil JG, et al. Recommendations for evaluation of prosthetic valves with echocardiography and doppler ultrasound: a report from the American Society of Echocardiography's Guidelines and standards committee and the task force on prosthetic valves, developed in conjunction with the American College of Cardiology Cardiovascular Imaging Committee, Cardiac Imaging Committee of the American Heart Association, the European Association of Echocardiography, a registered branch of the European Society of Cardiology, the Japanese Society of Echocardiography and the Canadian Society of Echocardiography, endorsed by the American College of Cardiology Foundation,
American Heart Association, European Association of Echocardiography, a registered branch of the European Society of Cardiology, the Japanese Society of Echocardiography, and Canadian Society of Echocardiography. J Am Soc Echocardiogr. 2009;22:975-1014, quiz 1082-1084.

14. Capps SB, Elkins RC, Fronk DM. Body surface area as a predictor of aortic and pulmonary valve diameter. J Thorac Cardiovasc Surg. 2000;119:975-82.

15. Ascoop CAPL, Van Zeijl LGPM, Pool J, Simoons ML. Cardiac exercise testing. Indications, staff, equipment, conduct and procedures. Neth J Cardiol. 1989;2:63-72.

16. Guazzi M, Adams V, Conraads V, et al. EACPR/AHA Scientific Statement. Clinical recommendations for cardiopulmonary exercise testing data assessment in specific patient populations. Circulation. 2012;126:2261-74.

17. Bleiziffer S, Eichinger WB, Hettich I, et al. Impact of patient-prosthesis mismatch on exercise capacity in patients after bioprosthetic aortic valve replacement. Heart. 2008;94:637-41.

18. Mishra RK, Li Y, Ricardo AC, et al. Association of N-terminal pro-B-type natriuretic peptide with left ventricular structure and function in chronic kidney disease (from the Chronic Renal Insufficiency Cohort [CRIC]). Am J Cardiol. 2013;111:432-8.

19. Meijers WC, Hoekstra T, Jaarsma T, van Veldhuisen DJ, de Boer RA. Patients with heart failure with preserved ejection fraction and low levels of natriuretic peptides. Neth Heart J. 2016;24:287-95.

20. Eindhoven JA, Menting ME, van den Bosch AE, et al. Associations between $\mathrm{N}$-terminal pro-B-type natriuretic peptide and cardiac function in adults with corrected tetralogy of Fallot. Int J Cardiol. 2014;174:550-6.

21. Luchner A, Behrens G, Stritzke J, et al. Long-term pattern of brain natriuretic peptide and $\mathrm{N}$-terminal pro brain natriuretic peptide and its determinants in the general population: contribution of age, gender, and cardiac and extra-cardiac factors. Eur J Heart Fail. 2013;15:859-67.

22. Luijnenburg SE, Peters RE, van der Geest RJ, et al. Abnormal right atrial and right ventricular diastolic function relate to impaired clinical condition in patients operated for tetralogy of Fallot. Int J Cardiol. 2013;167:833-9.

23. van Slooten YJ, van Melle JP, Freling HG, et al. Aortic valve prosthesis patient mismatch and exercise capacity in adult patients with congenital heart disease. Heart. 2016;102:107-13.

24. Norozi K, Buchhorn R, Kaiser C, et al. Plasma N-terminal probrain natriuretic peptide as a marker of right ventricular dysfunction in patients with tetralogy of Fallot after surgical repair. Chest. 2005;128:2563-70.

25. Bove T, Vandekerckhove K, Devos D, et al. Functional analysis of the anatomical right ventricular components: should assessment of right ventricular function after repair of tetralogy of Fallot be refined? Eur J Cardiothorac Surg. 2014;45:e6-12. 